\title{
La observación de la estructura textual de los libros para la catalogación de materias en las bibliotecas universitarias de la UNESP
}

\author{
A observação da estrutura textual de livros e sua contribuição para a catalogação \\ de assuntos em bibliotecas universitárias da UNESP
}

The contribution of the observation of the textual structure of books to subject cataloguing: a case study in the UNESP university libraries

\author{
Daniela Majorie dos ReIS (1), Mariângela Spotti Lopes FUJITA (2) \\ Faculdade de Filosofia e Ciências - UNESP, - Av. Hygino Muzzi Filho, 737 Marília - São Paulo - Brasil - CEP: 17525-900. (1) \\ correo electrónico. (2) fujita@marilia.unesp.br
}

\begin{abstract}
Resumen
La indexación es una forma de descripción que busca determinar conceptos expresos en un documento y representarlos de acuerdo con un lenguaje documental. Existen factores que pueden contribuir para una selección más completa de los términos que representarán el documento, tales como la observación de su estructura textual y el contexto de actuación profesional del indexador. El análisis de la estructura textual del libro puede ser realizada de una forma que facilite la indexación, pues el profesional puede preconocer las partes del texto en que localiza e identifica los términos más representativos del contenido textual. De esta forma, se busca comprender e investigar, con la aplicación del Protocolo Verbal, el uso que el indexador de bibliotecas de la UNESP realiza de la estructura textual durante la determinación de asuntos, de manera que se pueda obtener la revelación de sus procedimientos, dificultades y restricciones mediante la exteriorización de pensamientos durante la grabación de la indexación. A partir del análisis de los datos fue posible constatar que el anverso de la hoja de portada, dorso de la hoja de portada, desenvolvimiento (capítulos), entre otras partes de la estructura del libro proporcionarán la determinación del mayor número de términos, tornándolas más importantes para la indexación.
\end{abstract}

Palabras clave: Indexación. Bibliotecas Universitárias. Estructura Textual de Libros. UNESP. Protocolo Verbal.

\section{Introdução}

É durante a leitura documentária que o profissional realiza a tarefa de indexação, quando extrai termos que representem o documento como um todo sem a necessidade de ler todo o seu conteúdo.

A indexação é uma forma de descrição que consiste em determinar os conceitos expressos

\begin{abstract}
The indexing is a kind of description whose aim is to establish concepts expressed in a document and representing them according to a documentary language. There are elements that can contribute to a more complete selection of terms that will represent the document, like the observation of its textual structure and the context where the indexing professional acts. The analysis of the book textual structure can be carried out in a way that facilitates the indexing, as the professional can foresee the parts of the text where he localizes and identifies the more representative terms of the textual content. In such a way, it is intended to comprehend and inquire, with the applying of Verbal Protocol, the use that Unesp libraries' indexers do from the textual structure during the determination of subjects in such a way as to obtain the disclosure of their procedures, difficulties and restrictions through the externalization of thoughts during the recording of the indexing task. From the data analysis, it was possible to find out that the right hand page, the back of the title page, the chapters and other parts of the book's structure provided the greater number of terms, becoming the most important ones for the indexing task.
\end{abstract}

Keywords: Indexing. University libraries. Books' Textual Structure. UNESP. Verbal Protocol.

em um documento e representá-lo de acordo com os termos adequados a uma linguagem documental (Guinchat, Menou, 1994, p. 31). Estes termos estão geralmente inseridos em registros catalográficos em bases de dados ou catálogos de bibliotecas, frutos da catalogação de documentos.

Para Mey (1995, p. 5) “a catalogação, como tecnicamente denominada, consiste na repre- 
sentação do item", e existem formas diferentes de registros catalográficos para a representação física e temática dos documentos de uma biblioteca.

Na UNESP(1), existe a cooperação de registros catalográficos entre bibliotecas, o que facilita 0 intercâmbio de informações visando facilitar o processo de catalogação dos documentos. Existem os seguintes tipos de registros catalográficos:

- Identidade total (IT) quando os campos do formato MARC (2) são idênticos, tanto no registro da base de dados servidora quanto no original, o registro é gravado em um arquivo e será adequado ao Padrão UNESP (Universidade Estadual Paulista, 2002) antes da sua importação para a base de dados;

- Registro aproveitável (RA): tem alguns campos idênticos e outros diferentes como, por exemplo, edição ou data; serão aproveitados os campos iguais, os restantes serão alterados e importados para a base como registros catalográficos novos e, posteriormente, deverão ser incorporados pela Rede BIBLIODATA (3);

Registros catalográficos não localizados (NL) em nenhuma das bases servidoras são indicativos de catalogação original (CO) para os documentos. (Fujita, Rubi e Boccato, 2009, p. 7).

Quando um documento não é encontrado ou ainda não foi catalogado em nenhuma base da rede cooperante, será necessário realizar a catalogação original (CO). O profissional que realiza a catalogação original e indexação do documento deverá estar mais atento às informações apresentadas de forma a representá-lo da forma mais correta possível, já que este será o primeiro registro na rede cooperante e poderá ser usado por outros bibliotecários.

A catalogação do livro visa representá-lo do ponto de vista da forma, e a indexação, do ponto de vista do seu conteúdo. Para a catalogação existe normalização quanto ao padrão de como realizá-la, enquanto que para a indexação as normas sugerem partes a serem consultadas para realizar este processo, mas não indica um padrão formalizado de análise do assunto, pois se trata de um processo intelectual que depende da cognição do indexador como leitor profissional.

Desta forma, não existindo um padrão para o processo de determinação de assuntos, observou-se a importância de analisar quais partes do livro podem ser consultadas visando o sucesso deste processo.

\section{O tratamento descritivo e temático da informação}

O tratamento da informação é realizado de duas formas distintas: descritiva ou temática. O tratamento descritivo analisa o documento do ponto de vista de forma, um exemplo é a catalogação.

\section{Mey (1995, p. 5) afirma que a catalogação:}

[...] é o estudo, preparação e organização de mensagens codificadas, com base em itens existentes ou passíveis de inclusão em um ou vários acervos, de forma a permitir interseção entre as mensagens contidas nos itens e as mensagens internas dos usuários.

Assim, a catalogação descritiva tem como principal função, representar os itens criando diversas formas de acesso ao usuário (tanto em bases de dados como em acervos), diferente da indexação que busca termos para representar o assunto do documento no registro catalográfico inserido em bases de dados.

Para Dias e Naves (2007, p. 17), o tratamento temático da informação tem forte carga particular, e busca caracterizar o documento do ponto de vista de seu conteúdo. É o processo por meio do qual o classificador e o indexador identificam e determinam de que assuntos tratam um documento (Dias; Naves; Moura, 2001, p. 206).

A primeira etapa do tratamento temático da informação é a análise de assunto, tarefa que está sujeita à interferência de diversos fatores relacionados ao profissional, como o nível de conhecimento prévio (que são informações adquiridas pelo leitor durante suas experiências profissionais e cotidianas) do assunto de que trata o documento, formação e experiência, subjetividade, além de fatores lingüísticos, cognitivos e lógicos.

\section{Para Vieira (1988, p. 43):}

A indexação é uma técnica de análise de conteúdo que condensa a informação significativa de um documento, através da atribuição de termos, criando uma linguagem intermediária entre o usuário e o documento.

Assim, a indexação demonstra a importância de seus processos para a Análise Documentária, que é definida como um conjunto de procedimentos efetuados com fim de expressar o conteúdo de documentos, sob formas destinadas a facilitar a recuperação da informação (Dias, Naves, 2007, p. 11).

Segundo Fujita (2003, p. 63), a indexação está dividida em dois estágios: $O$ analítico, onde $\mathrm{O}$ profissional realiza a compreensão do texto como um todo para realizar a identificação e 
seleção de conceitos considerados importantes para a indexação. E o estágio da tradução, que consiste na representação de conceitos pelas linguagens de indexação. Em ambos os estágios observa-se o grau de proficiência do indexador, o que definirá a qualidade da indexação, e conseqüentemente a recuperação do documento pelos usuários.

Reforçando esta idéia, a NBR 12676 (1992, p. 2) apresenta no item 4.1 os "Estágios da indexação":

1. Exame do documento e estabelecimento do assunto de seu conteúdo;

2. Identificação dos conceitos presentes no assunto;

3. Tradução desses conceitos nos termos de uma linguagem de indexação;

A norma ainda expõe que para cada um destes estágios necessita do auxílio de instrumentos de indexação como tesauros, códigos de classificação, cabeçalhos de assunto e etc.

\section{A indexação de livros em bibliotecas universitárias}

Para Lancaster (2004), a indexação é feita visando atender às necessidades de determinados usuários.

Desta forma, se determinada biblioteca for especializada, deve-se realizar a indexação tendo em vista a especificidade de cada documento, levando em conta que os usuários já possuem algum conhecimento dentro de determinada área, realizando assim, buscas com termos mais específicos.

Em bibliotecas cujo acervo possui diversas áreas do conhecimento e que conseqüentemente recebem um público variado, como uma biblioteca pública, não há necessidade de realizar a indexação de forma muito detalhada e com termos específicos, pois os usuários provavelmente não encontrarão os documentos que procuram, por não usar termos de busca muito detalhados. Em bibliotecas universitárias, ocorre o contrário, pois devido ao envolvimento dos usuários com os cursos e departamentos da universidade, existe um conhecimento maior com relação aos termos usados em buscas por assunto.

O profissional da informação como responsável pela representação de documentos pode receber três diferentes denominações: classificador, indexador e catalogador.

Na visão de Fujita, Rubi e Boccato (2009, p. 4):
[...] é apropriado esclarecer que o catalogador, quando realiza a análise de assunto, deverá ser entendido como indexador, uma vez que a própria área de pesquisa reconhece a indexação e a catalogação de assuntos como conceitualmente equivalentes na concepção de Lancaster (1993), Silva e Fujita (2004) e Milstead (1983) entre outros. A razão de existirem como dois ramos da análise de assunto advém da procedência da atividade de cada uma, pois a catalogação de assuntos está essencialmente ligada à construção de catálogos de bibliotecas e a indexação à construção de índices de bibliografias em serviços de informação bibliográficos que produzem bases de dados.

Dentro de qualquer unidade de informação, especializada ou não, o indexador raramente terá muito tempo disponível para ler um documento do início ao fim visando à identificação de termos que o representem. Isso ocorre devido à grande quantidade de documentos para indexar, assim, o profissional deverá realizar uma leitura mais rápida e eficiente.

Como não existe um padrão formalizado que dê diretrizes para o processo de determinação de assuntos, torna-se necessária a observação do processo realizado pelo profissional para identificar seus procedimentos e estratégias quanto à exploração da estrutura textual de livro e analisar comparativamente, dentre as partes recomendadas pela literatura, quais ele consulta.

Lancaster (2004, p. 24), com base na ISO 5963 recomenda partes do livro que devem ter maior atenção do profissional durante a indexação. Geralmente são partes que apresentam a maior quantidade de informações sobre o conteúdo do documento, como: título; resumo se houver; sumário; introdução, as frases e parágrafos de abertura de capítulos, e as conclusões; lustrações, gráficos, tabelas e respectivas legendas; e palavras ou grupos de palavras que apareçam sublinhados ou grafados com tipos diferentes.

Segundo o mesmo autor, é necessária a observação de todos ou a maioria desses elementos, já que a indexação por título não é recomendada, podendo fazer uma representação errônea do documento.

A NBR 12676 (1992, p. 2), tradução da norma ISO 5963, também recomenda tópicos no documento que devem ser considerados durante a análise do documento, semelhantes aos de Lancaster (2004).

Vários autores apresentam sugestões com relação às partes mais importantes de um documento com o objetivo de facilitar e agilizar o processo de indexação. Mas, de maneira geral, não há uma regra formalizada que defina a or- 
dem de leitura que os catalogadores de assunto devem seguir no ato da indexação, diferente da catalogação descritiva que possui um manual padronizado de procedimentos, o MARC 21.

Portanto, observa-se que muitos catalogadores de assunto usam estratégias próprias ou profissionais durante a catalogação de assunto de documentos, e ambas podem trazer resultados satisfatórios na representação do item, principalmente quando envolve a observação da estrutura textual do livro.

\section{O livro e sua estrutura textual}

Torna-se necessário conceituar o livro e fazer considerações com relação a sua estrutura textual. Será exposto a seguir um sucinto histórico do livro, desde seu surgimento como manuscrito até suas técnicas atuais de apresentação, onde faremos articulações a respeito de sua estrutura textual.

Para Martins (2001, p. 93), o manuscrito apresenta conteúdos sobre qualquer assunto, é escrito a mão em suportes diversos, não somente em papel, papiro ou pergaminho, é o texto original do autor.

Os manuscritos podem ser registrados em vários tipos de suportes, sempre à mão com ou sem o auxílio de instrumentos. Guedes (2001, p. 23) mostra que os primeiros documentos em xilografia são do século VII, e os textos tipográficos mais antigos são compostos por caracteres móveis de metal, cujo processo de fundição foi perdido.

O advento da imprensa e das tipografias tornou o processo de registro da escrita mais simples e padronizado, o que não ocorria em manuscritos.

Para Febvre e Martin (1992, p. 355), nos séculos que precederam o advento da imprensa, os encarregados de reproduzir livros à mão adaptavam a produção visando atender as necessidades. Na primeira parte do século XV havia oficinas que reproduziam os livros mais procurados em grande quantidade, mostrando a vantagem na reprodução mecânica de textos mais requisitados.

Os livros impressos até 1500, denominados como "incunábulos" (do latim incunabulum, berço) (Martins, 2001, p. 157) eram produzidos, nos primeiros decênios da criação da imprensa, pelos impressores com o mesmo aspecto de obras manuscritas (Guedes, 2001, p. 24).

Com o aperfeiçoamento das técnicas de confecção do livro ao longo dos séculos, sua estrutura textual também mudou para uma forma de apresentação mais padronizada, facilitando e efetivando o trabalho do bibliotecário, tanto no tratamento descritivo quanto no tratamento temático da informação.

Para Febvre e Martin (1992, p. 128), atualmente:

[...] o leitor que abre um livro novo sabe que encontrará imediatamente, a partir da primeira página, todas as informações que lhe aconselharão sua leitura ou que, pelo contrário, o incitarão a não ir mais adiante: na página de rosto estão indicados o nome do autor, o título da obra, o local da edição, o nome do editor e a data de publicação.

Observa-se que atualmente existem formas padronizadas para a impressão de livros, o que não ocorria, na visão dos mesmos autores, em manuscritos e nos mais antigos livros impressos. Não havia folha de rosto e na maioria das vezes o texto iniciava-se logo após o nome do autor na primeira página.

Ainda na visão de Febvre e Martin (1992, p. 130), a página de rosto surgiu a partir da atitude de tipógrafos para evitar que o início do texto se manchasse, pois a primeira folha do livro era a que tinha mais tendência a se sujar e se empoeirar. Surgiu então a idéia de imprimir o texto no verso da primeira folha, depois começaram a imprimir o título, visando facilitar a identificação da obra. Foi desta forma que a partir de 14751480 surge a página de rosto.

O que era uma boa forma de apresentação dos livros para os editores da época, tornou-se hoje uma forma de padronização para livros, facilitando o trabalho dos profissionais da informação.

Assim como a apresentação da folha de rosto evoluiu com o aperfeiçoamento de técnicas editoriais, a apresentação do livro seguiu o mesmo curso. Os primeiros incunábulos apresentavam elementos semelhantes, se não iguais aos dos manuscritos, com a mesma disposição geral, abreviações e escrita fechada, que continuou dessa forma por um longo período (Febvre e Martin, 1992, p. 135).

Observa-se que, com o aperfeiçoamento das técnicas de edição, o livro se torna um instrumento com informações mais completas e bem dispostas, tanto na sua apresentação, quanto na disposição de seu conteúdo.

A NBR 6029 (2006, p. 4), norma de "informação e documentação de livros e folhetos" explica que o livro é composto por parte interna e externa. A parte interna é a mais relevante quanto ao conteúdo do documento e mais usada durante o processo de indexação. 
De acordo com a norma, a parte interna de livros e folhetos deve ser composta por:

Elementos pré-textuais:

- Falsa folha de rosto (elemento opcional);

- Folha de rosto (elemento obrigatório);

- Errata (elemento opcional);

- Dedicatória (elemento opcional);

- Agradecimento (elemento opcional);

- Epígrafe (elemento opcional);

- Lista de ilustrações (elemento opcional);

- Lista de tabelas (elemento opcional);

- Lista de abreviaturas e siglas (elemento opcional);

- Lista de símbolos (elemento opcional);

- Sumário (elemento obrigatório).

Elementos textuais: Parte em que é desenvolvido o conteúdo, antecedida, opcionalmente, por prefácio e/ou apresentação (a norma não define em tópicos a estrutura que o livro deve possuir).

Elementos pós-textuais:

- Posfácio (elemento opcional);

- Referências;

- Glossário (elemento opcional);

- Apêndice (elemento opcional);

- Anexo (elemento opcional);

- Índice (elemento opcional);

- Colofão (elemento obrigatório).

Os livros são meios de informação importantes, cuja publicação aperfeiçoou-se através dos séculos com o aprimoramento de técnicas de edição e publicação a partir de adventos tecnológicos. Com a NBR 6029 de 2006 observou-se que algumas normas, cujo objetivo é padronizar a publicação de livros, facilitam o trabalho de edição, tratamento descritivo e temático de livros.

\section{Metodologia}

A técnica de Protocolo Verbal visa mostrar os processos metacognitivos da mente humana a partir da transcrição das falas na íntegra após a realização de alguma atividade "pensando alto" (exteriorizando seus pensamentos e opiniões a respeito do assunto).
Fujita, Nardi e Fagundes (2003, p. 2) definem Protocolo Verbal como relatos verbais dos processos mentais conscientes do informante.

Foram analisados seis protocolos verbais individuais de catalogadores de seis bibliotecas universitárias dos cursos de Odontologia e Pedagogia que apresentam os procedimentos, estratégias e a exploração da estrutura textual durante o processo de catalogação de assuntos de livros.

A forma de análise dos protocolos verbais, que levou em consideração a estrutura do texto indexado foi definida com base nas pesquisas realizadas por Rubi (2004) e Silveira (2006).

\section{Análise dos Protocolos Verbais}

A partir das análises dos Protocolos Verbais Individuais das áreas de Pedagogia e Odontologia, com relação à observação da estrutura textual do livro, observou-se que todos os profissionais optaram por consultar principalmente a catalogação na fonte e outras informações contidas na folha de rosto, resumo, orelhas do livro e última capa.

Observou-se, também, que as regras específicas determinadas pela instituição foram realizadas a risca por todos os catalogadores das áreas de Pedagogia e de Odontologia. Todos pesquisavam por registros catalográficos anteriores que poderiam ser aproveitados em várias bases como no Bibliodata e Library of Congress, sempre seguindo o "Padrão de qualidade de registros catalográficos e bibliográficos da UNESP" que a CGB estabeleceu para a catalogação em todas as unidades da UNESP.

As principais partes consultadas pelos catalogadores na área de Pedagogia de acordo com o tipo de registro catalográfico estão demonstradas no Quadro I. 


\begin{tabular}{|c|c|c|c|}
\hline $\begin{array}{l}\text { Identidade } \\
\text { Total }\end{array}$ & $\begin{array}{l}\text { Título } \\
\text { Autor } \\
\text { Imprenta }\end{array}$ & $\begin{array}{l}\text { Última capa } \\
\text { Catalogação } \\
\text { na fonte } \\
\text { Anverso da } \\
\text { folha de rosto }\end{array}$ & $\begin{array}{l}\text { Anverso da } \\
\text { folha de rosto } \\
\text { Verso da } \\
\text { folha de rosto }\end{array}$ \\
\hline $\begin{array}{l}\text { Registro } \\
\text { Aproveitável }\end{array}$ & $\begin{array}{l}\text { Título } \\
\text { Autor }\end{array}$ & $\begin{array}{l}\text { Título } \\
\text { Imprenta }\end{array}$ & $\begin{array}{l}\text { Ficha } \\
\text { catalográfica }\end{array}$ \\
\hline $\begin{array}{l}\text { Catalogação } \\
\text { original }\end{array}$ & $\begin{array}{l}\text { Título } \\
\text { Autor } \\
\text { Imprenta }\end{array}$ & $\begin{array}{l}\text { Catalogação } \\
\text { na fonte } \\
\text { Última capa } \\
\text { Anverso da } \\
\text { folha de rosto }\end{array}$ & $\begin{array}{l}\text { Sumário } \\
\text { Prefácio }\end{array}$ \\
\hline $\begin{array}{l}\text { Entrevista } \\
\text { retrospectiva }\end{array}$ & $\begin{array}{l}\text { Folha de } \\
\text { rosto } \\
\text { Resumo } \\
\text { Orelhas do } \\
\text { livro }\end{array}$ & ----- & ----- \\
\hline
\end{tabular}

Quadro I. Análise de partes consultadas no livro para determinação de assuntos - Área de Pedagogia.

Nos Protocolos Verbais Individuais da área de Odontologia, os três catalogadores consultaram principalmente a folha de rosto com a justificativa de que é a fonte mais confiável para extrair informações sobre o livro.

Observa-se, a partir do Quadro II, que os catalogadores da área de Pedagogia consultaram as mesmas partes nos livros, ou semelhantes, mesmo quando os registros catalográficos usados eram diferentes.

\begin{tabular}{|c|c|c|c|}
\hline & Biblioteca A & Biblioteca $B$ & Biblioteca C \\
\hline $\begin{array}{l}\text { Identidade } \\
\text { Total }\end{array}$ & Título & ---- & ---- \\
\hline $\begin{array}{l}\text { Registro } \\
\text { Aproveitável }\end{array}$ & $\begin{array}{l}\text { Título } \\
\text { Sumário }\end{array}$ & ----- & $\begin{array}{l}\text { Sumário } \\
\text { Título }\end{array}$ \\
\hline $\begin{array}{l}\text { Catalogação } \\
\text { original }\end{array}$ & $\begin{array}{l}\text { Título } \\
\text { Catalogaçã } \\
\text { o na fonte } \\
\text { Ficha } \\
\text { catalográfic } \\
\text { a }\end{array}$ & $\begin{array}{l}\text { Capa } \\
\text { Ultima capa } \\
\text { Verso da } \\
\text { folha de } \\
\text { rosto }\end{array}$ & $\begin{array}{l}\text { Título } \\
\text { Anverso da } \\
\text { folha de rosto } \\
\text { Verso da } \\
\text { folha de rosto } \\
\text { Desenvolvim } \\
\text { ento } \\
\text { (capítulos do } \\
\text { livro) }\end{array}$ \\
\hline $\begin{array}{l}\text { Entrevista } \\
\text { retrospectiva }\end{array}$ & ---- & ---- & ---- \\
\hline
\end{tabular}

Quadro II. Análise de partes consultadas no livro para determinação de assuntos - Área de Odontologia.

A partir dos resultados apresentados, observouse que os catalogadores agem da mesma forma na maioria dos processos. Isso ocorre devido ao fato de trabalharem em bibliotecas da UNESP, onde existe um padrão a ser seguido, e devido à vasta experiência adquirida durante a catalogação de assuntos de livros em um ambiente de biblioteca universitária onde estão implantados os cursos de Pedagogia e Odontologia.
Com os resultados obtidos, observa-se que cada bibliotecário apresenta particularidades relacionadas tanto de seu conhecimento prévio sobre o assunto quanto do contexto e área de domínio em que está inserido.

Durante a catalogação de assuntos, alguns bibliotecários não identificaram termos para representar o documento (biblioteca A de Pedagogia e biblioteca $B$ de Odontologia), e/ou não consultaram partes do livro relevantes para uma indexação de qualidade: biblioteca A de Pedagogia - Título, biblioteca B de Pedagogia, catalogação na fonte, biblioteca $C$ de Pedagogia ficha catalográfica, biblioteca $A$ de Odontologia - título, biblioteca B de Odontologia - capa, biblioteca C de Odontologia - título.

Algumas das partes citadas nos quadros são recomendadas pela NBR 6029 (2006, p. 4), norma de "informação e documentação de livros e folhetos" (como anverso e verso da folha de rosto), que em conjunto com outros elementos, podem trazer resultados satisfatórios para 0 processo de indexação.

$O$ fato dos catalogadores terem consultado algumas partes individualmente deve-se aos tipos de registros catalográficos (IT e RA) proporcionados pela cooperação de registros catalográficos entre bibliotecas da rede UNESP. Os catalogadores que realizaram buscas pelo título em determinados tipos de registros catalográficos (IT e RA) não usaram necessariamente essa parte do livro para determinar o assunto do livro, muitas vezes essa é a única parte observada por existir uma confiança muito grande na cooperação de registros catalográficos oferecida pelo Bibliodata e outras bibliotecas da rede.

Apesar da vasta exploração da estrutura textual apresentada nas seis bibliotecas, apenas alguns catalogadores identificaram termos consultando partes relevantes para a indexação (partes que apresentam mais conteúdo sobre o assunto do livro), como na Biblioteca C - área de Pedagogia, cujo catalogador recuperou termos consultando o sumário e o prefácio. $\mathrm{O}$ catalogador de C - área de Odontologia identificou um termo no desenvolvimento do livro - elementos textuais.

O catalogador da Biblioteca B - área de Pedagogia recuperou mais termos em partes pouco recomendadas para o processo de indexação, como catalogação na fonte e última capa. Os catalogadores restantes identificaram nenhum ou poucos termos a partir de partes pouco relevantes para a indexação. 


\section{Considerações finais}

Todos os catalogadores analisados observaram a estrutura textual dos livros, além de mostrar interesse através de comentários e opiniões construtivas. Contudo, nenhum dos catalogadores analisados apresenta estratégias diretamente relacionadas à exploração da estrutura textual dos livros catalogados, ou seja, a determinação do assunto e sua representação por termos não foi realizada pela exploração da estrutura textual. Semelhantes resultados foram observados por Fujita e Rubi (2006) ao observarem que não existia uma sistematização de processos entre a exploração da estrutura textual de artigos científicos e identificação de conceitos.

A partir das análises apresentadas, constatou-se que os catalogadores seguem, sem metodologia definida, um processo de indexação na catalogação determinado pela experiência e pelas regras da biblioteca, onde os processos são realizados a partir de padrões de catalogação.

Os resultados das análises demonstraram as partes mais consultadas pelos catalogadores e quais delas levaram a identificação de termos para a representação do documento. A maioria das partes consultadas que trouxeram resultados relevantes são sugeridas pela norma, mostrando quais partes na estrutura textual de livros podem ser observadas visando a resultados mais satisfatórios para a indexação dos mesmos, como título, resumo, sumário e folha de rosto, desta forma, facilitando e padronizando este processo.

Portanto, recomendamos que, durante a indexação de livros em bibliotecas universitárias sejam observados pontos na estrutura textual na seguinte ordem: anverso da folha de rosto, prefácio, sumário, e desenvolvimento (capítulos do livro) e o último item, consultado quando o catalogador de assunto observar a necessidade de conferir os termos já identificados nos três primeiros itens sugeridos.

Em pesquisas futuras, visando obter resultados mais concretos, recomenda-se a coleta de dados somente a partir da observação da catalogação original de livros, quando o catalogador realizará pela primeira vez a indexação, sem o auxílio de registros catalográficos já existentes.

\section{Notas}

(1) Universidade Estadual Paulista, Brasil.

(2) MARC é um acrônimo de Machine-Readable Cataloging: um conjunto de padrões para identificar, armazenar, e comunicar informações bibliográficas em formato legível por máquina, de forma que diferentes computadores e programas possam reconhecer, processar e es- tabelecer pontos de acesso dos elementos que compõem a descrição bibliográfica (Alves e Souza, 2007, p. 25).

(3) Rede cooperativa de Bibliotecas brasileiras que tem seus acervos representados no Catálogo Coletivo Bibliodata, realizam a catalogação cooperativa e compartilham produtos e serviços, visando a redução dos custos, além de promover a difusão dos acervos bibliográficos de suas instituições.

(4) A Coordenadoria Geral de Bibliotecas (CGB) foi inicialmente denominada Biblioteca Central da Unesp. Instalada pela Resolução Unesp no 10 em 13 de junho de 1977, em nível Departamental, era subordinada ao Gabinete do Reitor, mas sediada na Faculdade de Filosofia, Ciências Sociais e da Documentação, Campus de Marília, uma vez que era ministrado o Curso de Biblioteconomia. Inicialmente, buscava-se a centralização de recursos, serviços e produtos, com a finalidade de evitar a duplicação dos mesmos, contudo respeitando-se a necessária descentralização dos acervos. Dessa forma, iniciou-se o trabalho para a constituição de um Catálogo Coletivo de Livros e Periódicos, bem como a implantação da aquisição centralizada de periódicos e aquisição planificada de livros.

\section{Referências}

Associação Brasileira de Normas Técnicas (1992). ABNT. NBR 12676: Métodos para análise de documentos: determinação de seus assuntos e seleção de termos de indexação. Rio de Janeiro, 1992.

Associação Brasileira de Normas Técnicas (2006). ABNT. NBR 6029. Informação e documentação: livros e folhetos: apresentação. Rio de Janeiro, 2006.

Dias, E. W.; Naves M. M. L.; Moura, M. A. (2001). O usuáriopesquisador e a análise de assunto. // Perspect. cienc. inf. Belo Horizonte. 6:2 (jul./dez. 2001) 205-221.

Dias, E. W., Naves; M. M. L. (2007). Análise de assunto: teoria e prática. Brasília: Thesaurus, 2007

Fujita, M. S. L.; Rubi, M. P, Boccato, V. R. C. (2009) O contexto sociocognitivo do catalogador em bibliotecas universitárias: perspectivas para uma política de tratamento da informação documentária. // Datagramazero: Revista de Ciência da Informação, Rio de Janeiro. 10:2 (abr. 2009) 1-21.

Fujita, M. S. L.; Nardi, M. I. A., Fagundes, S. A. (2003). A observação da leitura documentária por meio de protocolo verbal. // Rodrigues, G. M., Lopes, I. L. (Org.). Organização e representação do conhecimento na perspectiva da ciência da Informação. Brasília: Thesaurus, 2003. 141-178. (Estudos Avançados em Ciência da Informação, 2)

Fujita, M. S. L.; Rubi, M. P. (2006). Um modelo de leitura documentária para a indexação de artigos científicos: princípios de elaboração e uso para a formação de indexadores. // Datagramazero. Rio de Janeiro. 7: 3 (2006) 1-18.

Fujita, M. S. L. (2003). A Identificação de conceitos no processo de análise de assunto para indexação. // Revista Digital de Biblioteconomia e Ciência da Informação, Campinas. 1:1 (Jul./dez. 2003) 60-90.

Febvre, L.; Martin, H. (1992). O aparecimento do livro. São Paulo: Unesp, 1992. 572 p. Tradução de Fulvia M. L. Moretto e Guacira Marcondes Machado.

Guedes, F. (2001). O livro como tema: HIstória Cultura Indústria. Lisboa: Verbo, 2001. $410 \mathrm{p}$

Guinchat, C.; Menou, M. (1994). Introdução geral às ciências e técnicas da informação e documentação. Brasília: IBICT, 1994. 
Lancaster, F. W. (2004). Indexação e resumos: teoria e prática. Brasília: Briquet de Lemos, 2004.

Martins, W. (2001). A palavra escrita: História do livro, da imprensa e da biblioteca. São Paulo: Ática, 2001.

Mey, E. S. A. (1995). Introdução à catalogação. Brasília: Briquet de Lemos, 1995.

Vieira, S. B. (1988). Indexação automática e manual: revisão de literatura. // Ciência da Informação, Brasília. 17:1 (jan./jun. 1988) 43-57.

Silveira, T. J. D. (2006). Leitura documentária para catalogação de assunto em ambiente de biblioteca universitária: análise de um modelo de leitura. Marília: Universidade Estadual Paulista, Faculdade de Filosofia e Ciências, 2006. 86f. Trabalho de Conclusão de Curso (Graduação em Biblioteconomia).

Recibido: 2010-04-15. Revisado: 2010-06-29. Aceptado: 2010-07-07.

Dos Reis, Daniela Majorie; Fujita, Mariângela Spotti Lopes. La observación de la estructura textual de los libros para la catalogación de materias en las bibliotecas universitarias de la UNESP. I/ Scire. (2010) 85-91. ISSN 1135-3716. 